\section{Evidence for Size and Charge Permselectivity of Rat Ascending Colon Effects of Ricinoleate and Bile Salts on Oxalic Acid and Neutral Sugar Transport}

\author{
Satish C. Kathpalia, Murray J. Favus, and Fredric L. Coe \\ University Program in Renal Medicine and Division of \\ Endocrinology, Michael Reese Hospital and University of \\ Chicago Pritzker School of Medicine, Chicago, Illinois 60616
}

A transmural fluxes of oxalate and neutral sugars across rat ascending colon in vitro, under short-circuit conditions, to characterize permeability barriers selective for size and charge. Ionic oxalate appears to be transported preferentially to sodium oxalate. Mucosal addition of taurocholate $(1 \mathrm{mM})$, deoxycholate $(1 \mathrm{mM})$, or ricinoleate $(1 \mathrm{mM})$ increased bidirectional oxalate fluxes, and the ricinoleate effects were independent of medium calcium. Bidirectional fluxes of uncharged sugar molecules fell sharply at molecular weights above 76 (molecular radius above $3 \AA$ ), and oxalate transport was retarded relative to that of uncharged molecules of similar size, suggesting that there is both size and charge permselectivity. Ricinoleate increased fluxes of all neutral molecules tested but changed neither the exclusion limits nor the cation selectivity of the epithelium. Bile salts and ricinoleate increase oxalate transport, probably by making more channels available, but do not alter size and charge selectivity.

\section{Introduction}

Inflammatory disease or extensive resection of small bowel may increase colon oxalate absorption and cause hyperoxaluria with nephrolithiasis (1-7). Excessive amounts of bile salts and fatty acids that reach the colon in these diseases could enhance oxalate absorption by specifically increasing oxalate permeability (8) or by altering the charge and size selectivity of the epithelium in general. Fatty acids complex calcium and could reduce

An abstract of this work was presented at the Annual Meeting of the American Society of Nephrology, December 1982, Chicago, Illinois.

Received for publication 25 October 1982 and in revised form 7 May 1984

J. Clin. Invest.

(c) The American Society for Clinical Investigation, Inc.

0021-9738/84/09/0805/07 $\$ 1.00$

Volume 74, September 1984, 805-811 luminal ionic calcium concentration and thereby raise free oxalate ion concentration favoring absorption (9). The present studies characterize the permeability of normal ascending colon to oxalate and to four neutral molecules of similar dimensions, and the effects on permselectivity of bile salts and ricinoleate. Colon epithelium seems to exclude molecules on the basis of both size and charge. Bile salts and fatty acids appear to increase access to the selectivity barrier but do not alter its selective properties.

\section{Methods}

Animal preparation. Male Sherman rats weighing $150 \mathrm{~g}$ (Camm Research Lab Animals, Wayne, NJ) were fed normal chow which contained $0.02 \%$ oxalate and were killed in the nonfasting state. Segments of ascending colon $(3 \mathrm{~cm}$ distal to cecum) were removed to measure oxalate fluxes.

In vitro flux measurements. Adjacent segments of ascending colon from the same animal were trimmed free of mesentery, rinsed in icecold saline, and mounted in lucite hemichambers with an exposed tissue area of $0.69 \mathrm{sq} \mathrm{cm}$. Mucosal and serosal reservoirs were filled with $10 \mathrm{ml}$ of phosphate-buffered Krebs Ringer solution $\left(37^{\circ} \mathrm{C}, \mathrm{pH}\right.$ 7.4) containing $140 \mathrm{mM} \mathrm{NaCl}, 13.5 \mu \mathrm{M} \mathrm{Na}$ oxalate, $0.125 \mathrm{mM} \mathrm{CaCl}_{2}$, $0.125 \mathrm{mM} \mathrm{MgSO}_{4}$, and $11 \mathrm{mM} \mathrm{D}$-glucose, and gassed continuously with $100 \%$ oxygen to provide adequate mixing. Unidirectional transmural fluxes were measured on adjacent segments by a modification of the technique of Ussing and Zerahn $(10,11)$, by the addition of $\left[{ }^{14} \mathrm{C}\right.$ ]oxalate (as oxalic acid, specific activity $74 \mathrm{Ci} / \mathrm{mol}$ [Amersham, Arlington Heights, IL]); $\left[{ }^{14} \mathrm{C}\right]$ thiourea (specific activity $100 \mathrm{Ci} / \mathrm{mol}, 1$ $\mathrm{mM}$ ); $\left[{ }^{3} \mathrm{H}\right]$ mannitol (specific activity $17.1 \mathrm{Ci} / \mathrm{mol}, 2 \mathrm{mM}$ ); or $\left[{ }^{3} \mathrm{H}\right]$ raffinose (specific activity $1.4 \mathrm{Ci} / \mathrm{mol}, 1 \mathrm{mM}$ ) to either mucosal or serosal reservoirs. 1-ml aliquots were removed from the initially unlabeled reservoir at 10-, 15-, or 20-min intervals, and radioactivity was measured by beta liquid scintillation spectroscopy. Steady state fluxes were calculated as previously described (12). Net flux $\left(J_{\text {net }}\right),{ }^{1}$ the difference between the absorptive mucosal-to-serosal flux $\left(J_{\mathrm{ms}}\right)$ and the

1. Abbreviations used in this paper: Gt, tissue conductance; Isc, shortcircuit current; $J_{\mathrm{ms}}$, absorptive mucosal-to-serosal flux; $J_{\text {net }}$, net flux; $J_{\mathrm{sm}}$, secretory serosal-to-mucosal flux; $P^{\mathrm{Ox}}=$ and $P^{\text {raf }}$ permeability coefficients of oxalate and raffinose, respectively; $P_{\mathrm{ms}}$, flux/medium concentration, mucosal to serosal; $P_{\mathrm{sm}}$, flux/medium concentration, serosal to mucosal. 
secretory serosal-to-mucosal flux $\left(J_{\mathrm{sm}}\right)$, was assigned a positive value for net absorption.

Electrical neutrality across the tissue was maintained with the short-circuiting technique of Field et al. (13). Transmural potential difference was abolished by automatic voltage clamps (Bioengineering Division, University of Iowa College of Medicine, Iowa City, Iowa) which passed a short-circuit current (Isc) across the mounted tissue after correction for the resistance of buffer between the agar bridges and tissue surface. Open-circuited transmural potential difference and tissue conductance $(\mathrm{Gt})$ were obtained periodically by briefly interrupting the short-circuit current. Steady state fluxes from each animal were used only when the Gt of the paired tissues agreed within $30 \%$.

The concentrations of ionic oxalate and oxalate complexes in the buffer were calculated with a computer program (14) from the concentrations of the buffer constituents and the association and dissociation constants for the complexes that may form at pH 7.4 (Table I). Since ionic oxalate cannot be measured directly, the validity of the computer program was assessed by measurement of ionic calcium in the buffer as calcium concentration was varied, by the use of a calcium-selective electrode (Space Stat 20; Orion Research, Inc., Cambridge, MA). Calculated and measured ionic calcium were highly correlated $(r$ $=0.982, n=6$ ) over the range of 0.125 to $0.5 \mathrm{mM}$ total calcium, in which our transport studies were performed. Throughout the range of oxalate used, the product of oxalate ion and ionized calcium was below the solubility product of $2.1 \times 10^{-9} \mathrm{M}^{2}$ (14).

Experimental protocols. In experiment 1, oxalate time course data were obtained at $8.26 \mu \mathrm{M}$ ionic oxalate to determine when steady state was reached. In experiment $2, \mathrm{NaCl}$ was replaced with equimolar concentrations of choline chloride, and oxalate was held constant at $13.5 \mu \mathrm{M}$ in order to vary the ratio of free ionic oxalate-to- $\mathrm{Na}$ oxalate concentration (Table I). In experiment 3, unidirectional fluxes of $\left[{ }^{14} \mathrm{C}\right]$ thiourea, $\left[{ }^{14} \mathrm{C}\right]$ erythritol, $\left[{ }^{3} \mathrm{H}\right]$ mannitol, and $\left[{ }^{3} \mathrm{H}\right]$ raffinose were determined. In experiment 4 , oxalate concentration was varied from $1.35 \mu \mathrm{M}$ to $27 \mu \mathrm{M}$ to determine whether transport was saturable. In experiment 5 , fluxes of oxalate and four neutral molecules of experiment 3 were measured during a control period for $\mathbf{4 5} \mathrm{min}$; then ricinoleate (1 $\mathrm{mM})$, sodium taurocholate $(1 \mathrm{mM})$, or sodium deoxycholate (1 $\mathrm{mM}$ ) was added to the mucosal reservoirs, and fluxes of oxalate and the neutral molecules were measured for an additional $45 \mathrm{~min}$. Ricinoleate effects were measured with and without calcium in the buffer. The calcium removed was not replaced with another cation.

Statistical analysis. The $t$ test was used to determine the significance

Table I. Calculated Forms of Oxalate in Krebs-Phosphate Buffer

\begin{tabular}{lccr}
\hline & \multicolumn{4}{l}{ Sodium concentration $(m M)$} \\
\cline { 2 - 4 } Constituent & 140 & \multicolumn{1}{l}{10} & \multicolumn{1}{l}{35} \\
\hline Total oxalate & $13.5(100)^{*}$ & $13.5(100)$ & $13.5(100)$ \\
lonic oxalate & $8.26(61)$ & $9.87(73)$ & $11.04(82)$ \\
Complexed oxalate & $(39)$ & $(27)$ & $(18)$ \\
$\quad \mathrm{NaOx}$ & $4.70(35)$ & $2.97(22)$ & $1.72(13)$ \\
$\mathrm{MgOx}$ & $0.22(1.6)$ & $0.26(1.9)$ & $0.28(2.0)$ \\
$\mathrm{CaOx}$ & $0.15(1.1)$ & $0.18(1.3)$ & $0.25(1.8)$ \\
$\mathrm{KOx}$ & $0.16(1.1)$ & $0.21(1.5)$ & $0.24(1.8)$
\end{tabular}

* Values are micromolar, numbers in parentheses are percentage of total buffer oxalate. of differences between $J_{\mathrm{ms}}$ and $J_{\mathrm{sm}}$ on adjacent segments from the same animal or between fluxes within or between two groups. Variance within groups was not assumed to be equal. Analysis of variance was used when means of more than two groups were compared. Regression analysis was performed by the method of least squares. All analyses were performed by conventional computer techniques (BMDP; University of California, Los Angeles).

\section{Results}

Experiment 1: steady-state oxalate fluxes. $\left[{ }^{14} \mathrm{C}\right]$ oxalate appeared in the initially unlabeled reservoirs within $10 \mathrm{~min}$ after addition to either the mucosal or serosal reservoirs that bathed ascending colon segments (Fig. 1). By $40 \mathrm{~min}$, oxalate $J_{\mathrm{ms}}$ and $J_{\mathrm{sm}}$ became constant, so steady state fluxes were calculated from data obtained after $\mathbf{4 0}$ min.

Experiment 2: species of oxalate transported. Sodium oxalate accounted for $90 \%$ of complexed oxalate at a medium $\mathrm{Na}$ level of $140 \mathrm{mM}$ and a total oxalate level of $13.5 \mu \mathrm{M}$ (Table I). Reduction of $\mathrm{Na}$ from 140 to $35 \mathrm{mM}$ by the replacement of $\mathrm{NaCl}$ with choline chloride increased ionic oxalate from 8.26 to $11.04 \mu \mathrm{M}$ and increased ionic oxalate $J_{\mathrm{ms}}$ and $J_{\mathrm{sm}}$ without changing $J_{\text {net }}$ (Table II). The apparent permeability coefficients for ionic oxalate $J_{\mathrm{ms}}$ and $J_{\mathrm{sm}}$ were calculated from the equations:

$J_{140}=\left[\mathrm{Ox}^{*}\right]_{140} \cdot P \mathrm{i}+[\mathrm{NaOx}]_{140} \cdot P \mathrm{c}$ and

$J_{35}=\left[\mathrm{Ox}^{=}\right]_{35} \cdot \mathrm{Pi}+[\mathrm{NaOx}]_{35} \cdot \mathrm{Pc}$,

where $J_{140}$ and $J_{35}$ are the $J_{\mathrm{ms}}$ fluxes of total oxalate $(13.5 \mu \mathrm{M}$ in medium) at $140 \mathrm{mM} \mathrm{Na}\left(J_{140}=108 \pm 15 \mathrm{pmol} \cdot \mathrm{cm}^{-2} \cdot \mathrm{h}^{-1}\right.$; $n=5)$ and $35 \mathrm{mM} \mathrm{Na}\left(J_{35}=168 \pm 7 \mathrm{pmol} \cdot \mathrm{cm}^{-2} \cdot \mathrm{h}^{-1} ; n=5\right)$; $\left[\mathrm{Ox}^{=}\right]_{140},\left[\mathrm{Ox}^{=}\right]_{35},[\mathrm{NaOx}]_{140}$, and $[\mathrm{NaOx}]_{35}$ are medium ionic oxalate and sodium oxalate concentrations at 140 and $35 \mathrm{mM}$ $\mathrm{Na}$ (Table I); and $P_{\mathrm{i}}$ and $P_{\mathrm{c}}$ are the apparent permeability coefficients $\left(P=\right.$ flux $/$ medium concentration) for ionic $J_{\mathrm{ms}}^{\mathrm{ox}=}$ and for the complex $J_{\mathrm{ms}}^{\mathrm{NaOx}}$, respectively. The two simultaneous equations were solved for each of the five individual measurements of $J_{\mathrm{ms}} ; P_{\mathrm{i}}=23.7 \pm 7.4 \quad(P<0.0009$ vs. 0$)$ and $P_{\mathrm{c}}$ $=-9.8 \pm 5.7 \mathrm{~cm} \cdot \mathrm{h}^{-1} \cdot 10^{3}(P$, not significant vs. 0$)$, respectively,

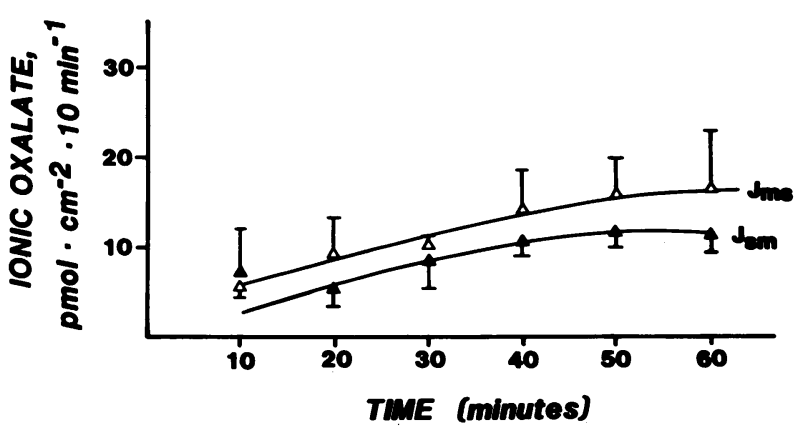

Figure 1. Unidirectional transmural fluxes of ionic oxalate across ascending colon. Values are mean \pm SEM for eight pairs of tissues. Medium ionic oxalate is $8.26 \mu \mathrm{M}$. 
Table II. Effects of Medium Sodium Reduction on Bidirectional Fluxes of Ionic Oxalate

\begin{tabular}{|c|c|c|c|c|c|c|}
\hline $\begin{array}{l}\text { Sodium } \\
\text { concentration }\end{array}$ & $n$ & $J_{m}$ & $J_{-}$ & $J_{\text {ma }}$ & Gt & Isc \\
\hline$m M$ & & $\mathrm{pmol} \cdot \mathrm{cm}^{-2} \cdot \mathrm{h}^{-1}$ & $\mathrm{pmol} \cdot \mathrm{cm}^{-2} \cdot \mathrm{h}^{-1}$ & $p m o \cdot \mathrm{cm}^{-2} \cdot \mathrm{h}^{-1}$ & $m \Omega^{-1} \cdot \mathrm{cm}^{-2}$ & $\mathrm{\mu A} \cdot \mathrm{cm}^{-2}$ \\
\hline 140 & 5 & $70 \pm 8^{*}$ & $58 \pm 6 \ddagger$ & $12 \pm 11$ & $11.1 \pm 0.7$ & $37.1 \pm 3.3$ \\
\hline 70 & 7 & $110 \pm 8$ & $93 \pm 8$ & $17 \pm 3$ & $12.7 \pm 0.7$ & $38.7 \pm 2.3$ \\
\hline 35 & 7 & $138 \pm 6$ & $122 \pm 9$ & $16 \pm 5$ & $12.3 \pm 0.4$ & $33.2 \pm 3.5$ \\
\hline
\end{tabular}

Values are mean \pm SEM for $n$ rats. Calculations of fluxes used the concentration of ionic oxalate listed in Table I. Gt and Isc values were not different for all fluxes. $* J_{\mathrm{ms}}(140)<J_{\mathrm{ms}}(70)<J_{\mathrm{ms}}$ (35); $P<0.02$. $\ddagger J_{\mathrm{sm}}(140)<J_{\mathrm{sm}}(70)<J_{\mathrm{sm}}(35) ; P<0.03$.

with no overlapping data points. The $P_{\mathrm{i}}$ for ionic oxalate is significantly different from no permeability, and the permeability of the $\mathrm{NaOx}$ complex, $P_{c}$, is not different from zero permeability. $P_{\mathrm{i}}$ and $\boldsymbol{P}_{\mathrm{c}}$ were significantly different from each other, $P<0.005$. Biological and technical variation contributed to intragroup variance, which was $35 \%$ of the mean, so some movement of $\mathrm{NaOx}$ may have occurred. However, the calculated difference between $P_{c}$ and $P_{i}$ is consistent with the concept that all of the radioisotopic movement of oxalate can be accounted for by the flux of ionic oxalate.

Experiment 3: permselectivity of colon to neutral molecules. Since molecular size and charge may influence the transport of oxalate across ascending colon, the bidirectional fluxes of the nonelectrolytes $\left[{ }^{14} \mathrm{C}\right]$ thiourea, $\left[{ }^{14} \mathrm{C}\right]$ erythritol, $\left[{ }^{3} \mathrm{H}\right]$ mannitol, and $\left[{ }^{3} \mathrm{H}\right]$ raffinose were measured under electrochemical neutrality. Steady state rates of transfer were reached by $30-45$ min for all molecules, and mean steady state values are shown

Table III. Effects of Ricinoleate on Oxalate and Neutral Sugar Steady State Unidirectional Fluxes Across Ascending Colon

\begin{tabular}{lccr}
\hline Compound & $J_{m}$ & $J_{m}$ & $J_{m}$ \\
\hline Oxalate + Ricin & $90 \pm 14$ & $117 \pm 11$ & $-27 \pm 14$ \\
& $173 \pm 18^{*}$ & $164 \pm 9^{*}$ & $9 \pm 20$ \\
Thiourea + Ricin & $27 \pm 3$ & $25 \pm 3$ & $2 \pm 4$ \\
& $40 \pm 2^{*}$ & $34 \pm 3$ & $6 \pm 4$ \\
Erythritol + Ricin & $9 \pm 1$ & $7 \pm 0.5$ & $2 \pm 1$ \\
& $19 \pm 2^{*}$ & $15 \pm 1^{*}$ & $4 \pm 2$ \\
Mannitol + Ricin & $24 \pm 2$ & $19 \pm 1$ & $5 \pm 2$ \\
& $44 \pm 3^{*}$ & $33 \pm 3^{*}$ & $11 \pm 4$ \\
Raffinose + Ricin & $7 \pm 1$ & $8 \pm 1$ & $-1 \pm 1$ \\
& $11 \pm 1^{*}$ & $12 \pm 1^{*}$ & $-1 \pm 2$ \\
\hline
\end{tabular}

Values are mean $\mathbf{S E M}$ for six to eight rats per group. Ricin is mucosal addition of $1.0 \mathrm{mM}$ ricinoleate; fluxes are picomoles per centimeter squared per hour for oxalate and nanomoles per centimeter squared per hour for all others. Medium total oxalate concentration is $13.5 \mu \mathrm{M}$ (ionic oxalate concentration is $8.26 \mu \mathrm{M}$ ).

* Greater than control, $P<0.05$. in Table III. $J_{\mathrm{ms}}$ and $J_{\mathrm{sm}}$ were not different and there was no net movement for any molecule. Polar nonelectrolytes with Stokes radii $>3 \AA$ all share similar values for $P_{\mathrm{ms}}$ and $P_{\mathrm{sm}}$ (Fig. 2, open symbols), whereas molecules with radii $<3 \AA$
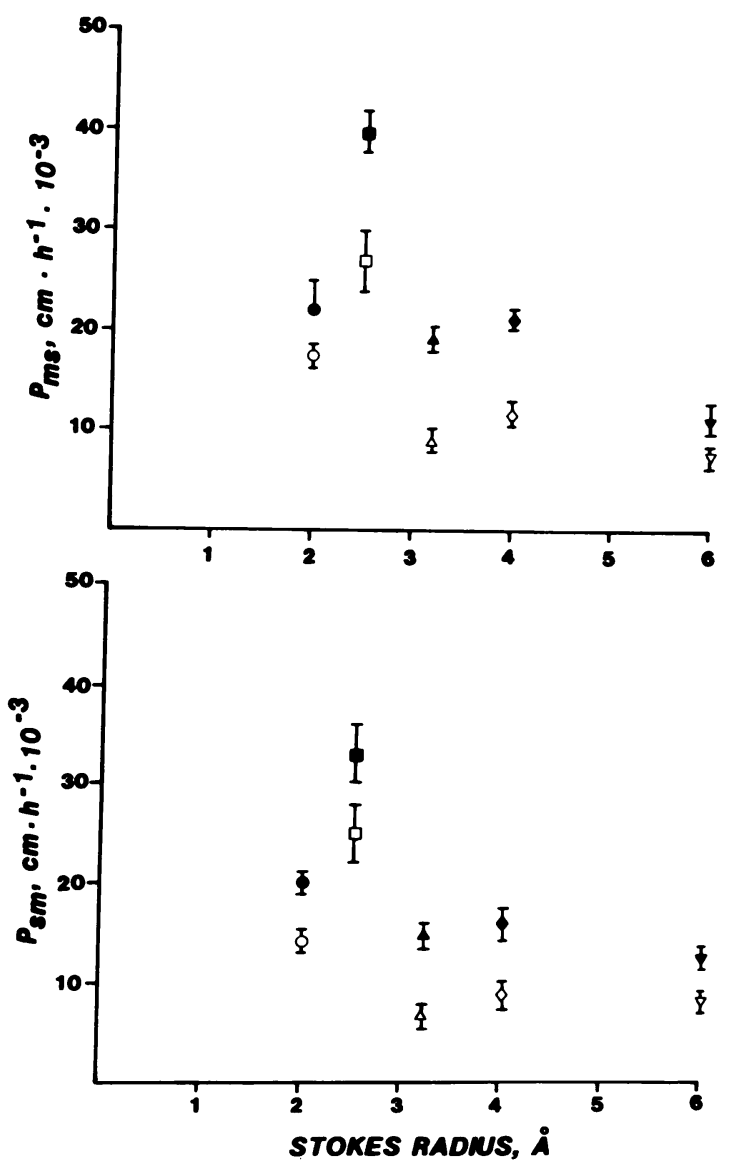

Figure 2. Apparent permeability coefficients of oxalate (O), thiourea $(\square)$, erythritol $(\Delta)$, mannitol $(0)$ and raffinose $(\nabla)$ in the absence (open symbols) and presence (solid symbols) of $1.0 \mathrm{mM}$ mucosal ricinoleate for the movement from mucosa to serosa $\left(P_{\mathrm{ms}}, t o p\right)$ and serosa to mucosa $\left(P_{\mathrm{sm}}\right.$, bottom $)$. Values are mean \pm SEM for six to eight paired tissues per condition. 


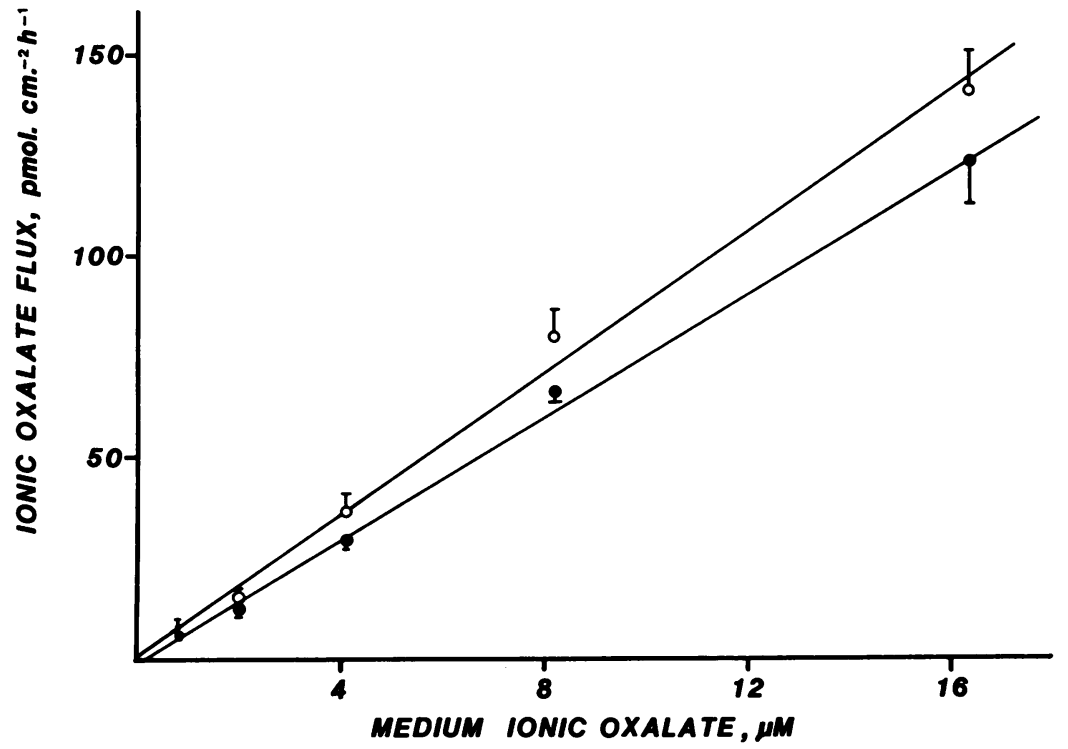

Figure 3. Ionic oxalate fluxes across ascending colon in the presence of medium ionic oxalate that varied from $0.8 \mu \mathrm{M}$ to $16.5 \mu \mathrm{M}$. Values are mean \pm SEM for seven rats for $J_{\mathrm{ms}}(0)$ and $J_{\mathrm{sm}}(\bullet)$. have greater mean values for both. Although ionic oxalate has a Stokes radius of $2.2 \AA$, oxalate $P$, mucosal to serosal $\left(P_{\mathrm{ms}}\right)$ and $P$, serosal to mucosal $\left(P_{\mathrm{sm}}\right)$ are less than that of thiourea (Stokes radius of $2.5 \AA$ ), suggesting that its charge reduces its permability.

Experiment 4: kinetic studies. Steady state oxalate $J_{\mathrm{ms}}$ and $J_{\mathrm{sm}}$ rose linearly as medium ionic oxalate was increased from 0.8 to $16.5 \mu \mathrm{M}$ (corresponding to total oxalate of 1.35 to 27 $\mu \mathrm{M}$ ) without a tendency to plateau (Fig. 3). Over the 20 -fold range of medium oxalate concentration employed, the flux ratios $\left(J_{\mathrm{ms}} / J_{\mathrm{sm}}\right)$ were consistently $>1.0$, ranging from 1.06 to 1.25 , but significant net absorption $\left(J_{\mathrm{ms}}>J_{\mathrm{sm}}\right)$ was reached only at a medium ionic oxalate level of $8.26 \mu \mathrm{M}(13.5 \mu \mathrm{M}$ total). Because this oxalate concentration also most closely approximated oxalate concentration in blood $(14 a, 14 b)$, it was used in subsequent experiments.

The transepithelial oxalate apparent permeability coefficient $\left(P^{\mathrm{Ox}=}\right)$ was determined for each unidirectional flux from: $P^{\mathrm{Ox}=}$
$=J^{\mathrm{Ox}}=/$ [oxalate] where oxalate is the ionic concentration. From the experiments in which medium ionic oxalate varied from 0.8 to $16.5 \mu \mathrm{M}$, ascending colon $P_{\mathrm{ms}}^{\mathrm{Ox}=}$ varied from $9.6 \pm 1.9$ to $8.5 \pm 0.6 \mathrm{~cm} \cdot \mathrm{h}^{-1} \cdot 10^{3} . P_{\mathrm{sm}}^{\mathrm{Ox}}=$ declined insignificantly, from $9.1 \pm 2.4$ to $7.5 \pm 0.6$. It appears, then, that the permeability of the pathway to ionic oxalate is not concentration dependent.

Experiment 5: effects of bile salts and ricinoleate. Under short-circuited conditions, the mucosal addition of $1.0 \mathrm{mM}$ taurocholate increased both oxalate $J_{\mathrm{ms}}$ and $J_{\mathrm{sm}}$ and caused no change in net oxalate movement (Table IV). Steady state was reached by $45 \mathrm{~min}$ in the absence and presence of taurocholate. Exposure of the mucosal surface to $1.0 \mathrm{mM}$ deoxycholate raised both $J_{\mathrm{sm}}$ and $J_{\mathrm{ms}}$ but did not change $J_{\text {net }}$. Both salts also increased raffinose $J_{\mathrm{ms}}$ and $J_{\mathrm{sm}}$ without changing $J_{\text {net }} . P^{\mathrm{Ox}}=$ and the permeability coefficient of raffinose $\left(P^{\text {raf }}\right)$ were well correlated in the absorptive and secretory directions in the absence and presence of deoxycholate (Fig. 4). Taurocholate also increased bidirectional oxalate and raffinose permeability coef-

Table IV. Effects of Taurocholate and Deoxycholate on Oxalate and Raffinose Fluxes in Ascending Colon

\begin{tabular}{|c|c|c|c|c|c|c|c|}
\hline \multirow[b]{2}{*}{ Condition } & \multirow[b]{2}{*}{$n$} & \multicolumn{3}{|l|}{ lonic oxalate } & \multicolumn{3}{|l|}{ Raffinose } \\
\hline & & $J_{\mathrm{mat}}$ & $J_{m}$ & $J_{\text {net }}$ & $J_{\mathrm{mat}}$ & $J_{\mathbf{m}}$ & $J_{\text {net }}$ \\
\hline Control & 8 & $105 \pm 13$ & $92 \pm 13$ & $13 \pm 21$ & $5 \pm 0.5$ & $6 \pm 1$ & $-1 \pm 1$ \\
\hline Taurocholate & 8 & $176 \pm 16^{*}$ & $160 \pm 16^{*}$ & $16 \pm 23$ & $9 \pm 1^{*}$ & $9 \pm 1 *$ & $0 \pm 1$ \\
\hline Control & 9 & $97 \pm 14$ & $101 \pm 11$ & $-4 \pm 16$ & $6 \pm 1$ & $5 \pm 0.5$ & $1 \pm 1$ \\
\hline Deoxycholate & 9 & $187 \pm 28^{*}$ & $204 \pm 23^{*}$ & $-17 \pm 39$ & $11 \pm 1^{*}$ & $10 \pm 1^{*}$ & $1 \pm 1$ \\
\hline
\end{tabular}

Values are mean \pm SEM. Fluxes are picomoles per centimeter squared per hour for oxalate, nanomoles per centimeter squared per hour for raffinose. Medium ionic oxalate concentration is $8.26 \mu \mathrm{M}$ and medium raffinose concentration is $1 \mathrm{mM}$. Positive values for $J_{\text {net }}$ are net absorption. * Differs from control, $P<0.02$. 


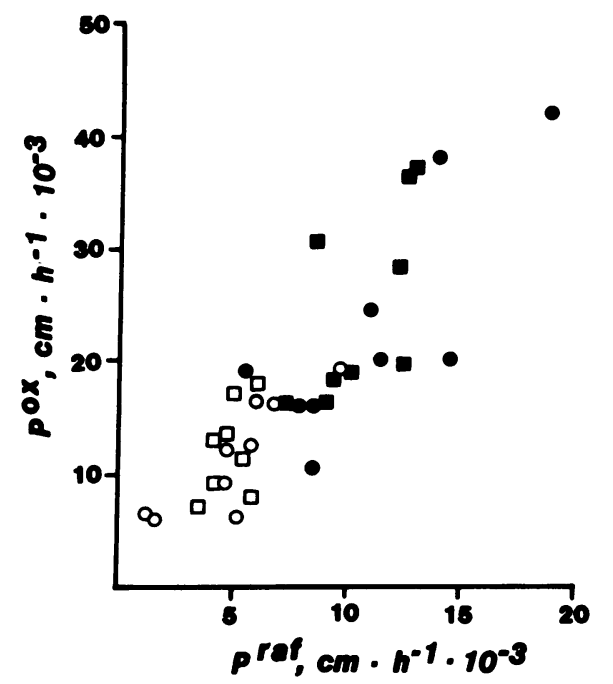

Figure 4. The apparent permeability coefficients of the oxalate and raffinose fluxes across ascending colon before (open symbols) and after (solid symbols) the mucosal addition of $1.0 \mathrm{mM}$ deoxycholate. Circles indicate $P_{\mathrm{ms}}$ and squares indicate $P_{\mathrm{sm}}$. For $P_{\mathrm{ms}}^{\mathrm{Ox}=}$ vs. $P_{\mathrm{ms}}^{\mathrm{mr}}$, predeoxycholate vs. postdeoxycholate, slope $=1.9 \pm 0.4$ vs. $2.07 \pm 0.5$; $r=0.89$ vs. $0.81 ; P$, not significant. For $P_{\mathrm{sm}}^{\mathrm{Ox}-}$ vs. $P_{\mathrm{sm}}^{\mathrm{raf}}$, predeoxycholate vs. postdeoxycholate, slope $=1.85 \pm 1.2$ vs. $2.6 \pm 1.1 ; r=0.5$ vs. $0.66 ; P$, not significant. For pooled $P_{\mathrm{ms}}^{\mathrm{Ox}=}$ vs. $P_{\mathrm{ms}}^{\mathrm{raf}}$, slope $=2.01 \pm 0.2, \mathrm{~F}$ ratio $=62.0, P<0.0001, n=17$. For pooled $P_{s m}^{\text {Ox- }}$ vs. $P_{s m}^{\text {raf }}$, slope $=2.35 \pm 0.4, \mathrm{~F}$ ratio $=36.3, P<0.0001, n=17$. The pooled slopes were not different.

ficients without changing the regression slope for $P_{\mathrm{ms}}^{\mathrm{Ox}}$ vs. $P_{\mathrm{ms}}^{\mathrm{raf}}$. The bidirectional apparent permeability coefficients were well correlated in the absence and presence of taurocholate and so were pooled. For $P_{\mathrm{ms}}^{\mathrm{Ox}-}$ vs. $P_{\mathrm{ms}}^{\mathrm{raf}}$, slope $=2.24 \pm 0.4, r=0.89, n$ $=16, P<0.001$; for $P_{\mathrm{sm}}^{\mathrm{Ox}-}$ vs. $P_{\mathrm{sm}}^{\mathrm{raf}}$ slope $=2.03 \pm 0.02, r=0.83$, $n=16, P<0.0001$. Regression slopes did not differ.

The removal of buffer calcium decreased oxalate and raffinose $J_{\mathrm{ms}}$ and $J_{\mathrm{sm}}$ but did not alter net oxalate or raffinose fluxes (Table V). The mucosal addition of $1.0 \mathrm{mM}$ ricinoleate increased oxalate, $J_{\mathrm{ms}}, J_{\mathrm{sm}}$, and $J_{\text {net }}$ in the presence and absence of buffer calcium (Table V). Ricinoleate also increased raffinose fluxes (Table V), but not raffinose $J_{\text {net }}$, independent of buffer calcium. Ricinoleate increased $\mathrm{Gt}$; removal of calcium increased Isc but not Gt (Table V).

The mucosal addition of $1.0 \mathrm{mM}$ ricinoleate increased $J_{\mathrm{ms}}$ and $J_{\mathrm{sm}}$ (Table III) and $P_{\mathrm{ms}}$ and $P_{\mathrm{sm}}$ (Fig. 2, solid symbols) for oxalate and all of the polar nonelectrolytes without changing their relationship to each other. There was no net movement of the compounds under basal conditions or after the addition of mucosal ricinoleate, and the agent caused no change in the time required to reach steady state (30-45 $\mathrm{min})$.

\section{Discussion}

Studied in vitro, ascending colon behaves as if it possesses transport sites that can exclude molecules on the basis of both radius and charge. Neutral sugar permeability increases as the molecular radius falls below $3 \AA$. Oxalate, which possesses two negative charges at $\mathrm{pH} 7.4$ (14), has a lower permeability than thiourea, which has a larger radius but no net charge. Charge selective channels are well described in Necturus gallbladder (15) and other epithelia (16), and the molecular size at which neutral molecules were retarded by rat colon is similar to that for rabbit gallbladder (17). Like gallbladder, colon generates low transepithelial potential (18), its basal sodium transport is not affected by amiloride (19), and transepithelial sodium flux is mainly electrically neutral (20). These typical characteristics of a leaky epithelium apply to gallbladder and colon.

Our studies suggest that oxalate is transported as an ion rather than a neutral uncharged complex. About $39 \%$ of medium oxalate existed as a complex in the phosphate buffer we used, and $90 \%$ of the complex was $\mathrm{NaOx}$. The molecular weight of this complex is 134 , large enough to be partially excluded from epithelial transport. Calculated permeabilities

Table V. Effects of Ricinoleate and Medium Calcium on Oxalate and Raffinose Fluxes Across Ascending Colon

\begin{tabular}{|c|c|c|c|c|c|c|c|c|c|c|}
\hline \multirow[b]{2}{*}{ Condition } & \multirow[b]{2}{*}{ [Ca] } & \multirow[b]{2}{*}{$n$} & \multicolumn{3}{|c|}{ lonic oxalate } & \multicolumn{3}{|l|}{ Raffinose } & \multirow[b]{2}{*}{ Gt } & \multirow[b]{2}{*}{ Isc } \\
\hline & & & $J_{m}$ & $J_{m}$ & $J_{m}$ & $J_{m}$ & $J_{-}$ & $J_{m a}$ & & \\
\hline Control & 0.125 & 6 & $90 \pm 14$ & $117 \pm 11 \ddagger$ & $-27 \pm 14$ & $7 \pm 1.0$ & $8 \pm 1.0 \ddagger$ & $-1 \pm 1.0$ & $14.9 \pm 0.8$ & $25.6 \pm 2.6$ \\
\hline Ricinoleate & 0.125 & 6 & $173 \pm 18^{*}$ & $164 \pm 9 * \ddagger$ & $9 \pm 20$ & $11 \pm 1.0^{*}$ & $12 \pm 1.0^{*} \ddagger$ & $-1 \pm 1.0$ & $17.9 \pm 0.9^{*}$ & $22.5 \pm 2.6$ \\
\hline Control & 0 & 9 & $71 \pm 5$ & $70 \pm 6$ & $1 \pm 5$ & $5 \pm 0.4$ & $4 \pm 0.3$ & $1 \pm 0.4$ & $15.1 \pm 0.6$ & $41.3 \pm 3.9^{\prime \prime}$ \\
\hline Ricinoleate & 0 & 9 & $147 \pm 10^{*}$ & $121 \pm 9^{*}$ & $26 \pm 11$ & $10 \pm 1.0^{*}$ & $8 \pm 0.5^{*}$ & $2 \pm 1.0$ & $19.9 \pm 0.8 * \S$ & $38.8 \pm 3.88^{\prime \prime}$ \\
\hline
\end{tabular}

Values are mean \pm SEM. Ricinoleate concentration in mucosal reservoir is $1.0 \mathrm{mM}$. [Ca] is medium calcium concentration (millimolar). Medium ionic oxalate is $8.26 \mu \mathrm{M}$; raffinose is $1.0 \mathrm{mM}$. Ionic oxalate fluxes are picomoles per centimeter squared per hour, raffinose fluxes are nanomoles per centimeter squared per hour. Gt is in $1 /$ milliohms per centimeter squared; Isc is in microamperes per centimeter squared. Fluxes for control $0.125 \mathrm{Ca}$ and ricinoleate $0.125 \mathrm{Ca}$ are identical to values for the experiment in Table III. * Differs from control, $P<0.05$. $¥$ Differs from 0 [Ca], $P<0.01$. § Differs from control 0.125 [Ca], $P<0.02$. "Differs from 0.125 [Ca], $P<0.01$. 
indicate that all of the oxalate transported at 140 and $35 \mathrm{mM}$ medium sodium can be accounted for by the movement of ionic oxalate. One assumption contained in the calculation of ionic $P_{\mathrm{ms}}^{\mathrm{Ox}}=$ and $P_{\mathrm{sm}}^{\mathrm{Ox}=}$ is that changing medium sodium does not alter membrane permeability. This is supported by previous studies $(21,22)$ in which we observed no change in calcium or mannitol $J_{\mathrm{ms}}$ or $J_{\mathrm{sm}}$ across ascending colon in which medium sodium varied from $140 \mathrm{mM}$ to zero. Also, ionic oxalate fluxes increased when medium ionic oxalate was increased by the replacement of medium sodium with choline. Other assumptions concern constants and equilibria (14). Our conclusion is based upon indirect evidence, and so definitive evidence for the preferred transport of ionic oxalate must await the development of an oxalate-specific ion electrode.

Mucosal taurocholate, deoxycholate, or ricinoleate increased bidirectional oxalate fluxes and permeability to raffinose. If driving forces for absorption were present, as they are in vivo, net absorption would increase. Ricinoleate increased permeability to oxalate and all four neutral molecules, but the Stokes radius at which the molecules were excluded was unaltered, and the relative retardation of oxalate transport persisted. These observations suggest that ricinoleate increased access to an aqueous channel by creating more pores through the epithelium or by increasing the number of tight junctional or brush border sites available for transport. An increase in the size of each pore would increase the size at which molecules were relatively excluded, which did not occur.

The effects of bile salts and ricinoleate we observed would explain previous reports of increased urea, EDTA, and inulin absorption by perfused rat colon $(8,23,24)$. Dobbins and Binder (8) have described reduced water absorption or net water secretion by rat colon perfused with bile salts or fatty acids, which could be the result of reduced active sodium absorption. These studies plus our observations make it unlikely that increased bidirectional oxalate transport was secondary to convective flow or solvent drag. Given ileal resection, jejunal bypass surgery, or severe ileal disease $(1-7,25,26)$, fatty acids and bile salts are delivered to the colon in excessive concentrations (27) and could cause oxalate overabsorption by raising permeability $(8,28,29)$. A low fat diet reduces their delivery and the degree of hyperoxaluria $(7,9)$. Our experiments do not support the hypothesis that ricinoleate acts by binding luminal calcium, as ricinoleate was active in the absence of calcium.

Removal of medium calcium increased Isc in the present study, increased Gt in rabbit ileum (30), and did not alter Isc or $\mathrm{Gt}$ in rat colon when calcium was replaced with magnesium (31). These apparent differences may be related to species or intestinal segmental differences, or to other constituents in the low calcium medium, such as magnesium.

The precise mechanisms of oxalate transport are not resolved completely by our present data. The lack of saturability is compatible with passive movement, as previously suggested $(32,33)$; however, we cannot exclude coupled movement to other ions, such as sodium or chloride, which may be more vigorous in vivo than in the static environment of the Ussing chamber. For example, secondary active transport as a result of chloride or bicarbonate movement $(34,35)$ might not be noted here, as our medium was bicarbonate free, and chloride concentrations were equal on both sides.

\section{Acknowledgments}

The authors gratefully acknowledge the technical contributions of Vimala Thatchet.

This study was supported in part by National Institutes of Health grant AM 20585 and by a grant from the Michael Reese Research Institute.

\section{References}

1. Maretka, A., and J. Nedbal. 1964. Urolithiasis as a complication of the surgical treatment of ulcerative colitis. Gut. 5:214-217.

2. Gelzayd, E. A., R. I. Breuer, and J. B. Kirsner. 1968. Nephrolithiasis in inflammatory bowel disease. Am. J. Dig. Dis. 13:1027-1034.

3. Smith, L. H., H. Fromm, and A. F. Hoffmann. 1968. Acquired hyperoxaluria nephrolithiasis and intestinal disease: description of a syndrome. N. Engl. J. Med. 286:1371-1375.

4. Smith, L. H. 1980. Enteric hyperoxaluria and other hyperoxaluric states. In Contemporary Issues in Nephrology. Vol. 5. F. L. Coe, B. M. Brenner, and J. H. Stein, editors. Churchill Livingstone Inc., New York

5. Chadwick, V. S., K. Modha, and R. J. Dowling. 1973. Mechanism for hyperoxaluria in patients with ileal dysfunction. N. Engl. J. Med. 289:172-176.

6. Earnest, D. L., G. Johnson, H. E. Williams, and W. H. Admirand. 1974. Hyperoxaluria in patients with ileal resection: an abnormality in dietary oxalate absorption. Gastroenterology. 66:11441122.

7. Dobbins, J. W., and H. J. Binder. 1977. Importance of the colon in enteric hyperoxaluria. N. Engl. J. Med. 296:298-301.

8. Dobbins, J. W., and H. J. Binder. 1976. Effect of bile salts and fatty acids on the colonic absorption of oxalate. Gastroenterology. 70:1096-1100.

9. Anderson, H., and R. Jagenburg. 1974. Fat-reduced diet in the treatment of hyperoxaluria in patients with ileopathy. Gut. 15:360366.

10. Ussing, H. H., and K. Zerahn. 1951. Active transport of sodium as the source of electric current in the short-circuited isolated frog skin. Acta Physiol. Scand. 23:110-127.

11. Favus, M. J., S. C. Kathpalia, F. L. Coe, and A. E. Mond. 1980. Effects of diet calcium and 1,25-dihydroxyvitamin $D_{3}$ on colon calcium active transport. Am. J. Physiol. 238:G75-G78.

12. Schultz, S. G., and R. Zalusky. Ion transport in isolated rabbit ileum: short-circuit current and Na fluxes. J. Gen. Physiol. 47:567587.

13. Field, M., D. Fromm, and I. McColl. 1971. Ion transport in rabbit ileal mucosa. I. Na and $\mathrm{Cl}$ fluxes and short-circuit current. Am. J. Physiol. 220:1388-1396.

14. Finlayson, B. 1977. Calcium stones: some physical and chemical aspects. In Calcium Metabolism in Renal Failure and Nephrolithiasis. D. S. David, editor. John Wiley and Sons, New York. 337

14a. Williams, H. E., G. A. Johnson, and L. H. Smith, Jr. 1971. 
The renal clearance of oxalate in normal subjects and patients with primary hyperoxaluria. Clin. Sci. 41:213-218.

14b. Hodgkinson, A., and R. Wilkinson. 1974. Plasma oxalate concentration and renal excretion of oxalate in man. Clin. Sci. Mol. Med. 46:61-73.

15. Fromter, E. 1972. The route of passive ion movement through epithelium of Necturus gallbladder. J. Membr. Biol. 8:259-301.

16. Fromter, E., and J. M. Diamond. 1972. Route of passive ion permeation in epithelia. Nat. New Biol. 235:9-13.

17. Steward, M. C. 1982. Paracellular transport in the gallbladder. In Electrolyte and Water Transport Across Gastrointestinal Epithelia. R. M. Case, A. Garner, L. A. Turnberg, and J. A. Young, editors. Raven Press, New York. 1-10.

18. Edmonds, C. J., and J. Marriott. 1968. Factors influencing the electrical potential across the mucosa of rat colon. J. Physiol. 194:457494.

19. Will, P. C., J. L. Lebowitz, and U. Hopfer. 1980. Induction of amiloride-sensitive sodium transport in the rat colon by mineralocorticoids. Am. J. Physiol. 238:F261-F268.

20. Binder, H. J., and C. L. Rawlins. 1973. Electrolyte transport across isolated large intestinal mucosa. Am. J. Physiol. 225:1232-1239.

21. Favus, M. J., S. C. Kathpalia, and F. L. Coe. 1981. Kinetic characteristics of calcium absorption and secretion by rat colon. $\mathrm{Am}$. J. Physiol. 240:G350-G354.

22. Favus, M. J., M. Berelowitz, and F. L. Coe. 1981. Effects of somatostatin on intestinal calcium transport in the rat. Am. J. Physiol. 241:G215-G221.

23. Bright-Asare, P., and H. J. Binder. 1973. Stimulation of colonic secretion of water and electrolytes by hydroxy fatty acids. Gastroenterology. 64:81-88.

24. Rummel, W., G. Nell, and R. Waintschke. 1975. Action mechanisms of antiabsorptive and hydragogue drugs. In Intestinal Absorption and Malabsorption. T. Z. Czaky, editor. Raven Press, New York. 209-227.

25. Barilla, D. E., C. Notz, D. Kennedy, and C. Y. C. Pak. 1978.
Renal oxalate excretion following oral oxalate loads in patients with ileal disease and with renal absorptive hypercalciurias. Am. J. Med. 64:579-585.

26. Hylander, E., S. Jarnum, K. Kempel, and M. Thale. 1980. The absorption of oxalate, calcium and fat after jejunoileal bypass: a prospective study. Scand. J. Gastroenterol. 15:343-348.

27. Mitchell, W. D., J. M. Findlay, R. J. Prescott, M. A. Eastwood, and D. B. Horn. 1973. Bile acids in the diarrhea of ileal resection. Gut. 14:348-353.

28. Chadwick, V. S., E. Elias, and G. D. Bell. 1975. The role of bile acids in the increased intestinal absorption of oxalate after ileal resection. In Advances in Bile Acid Research. S. Matern, J. Hackenschmidt, P. Back, and W. Gerok, editors. Springer Verlag, Berlin. 435438.

29. Saunders, D. R., J. Sillery, and G. B. McDonald. 1975 Regional differences in oxalate absorption by rat intestine: evidence for excessive absorption by the colon in steatorrhea. Gut. 16:543-554.

30. Bolton, J. E., and M. Field. 1977. Ca ionophore-stimulated ion secretion in rabbit ileal mucosa: relation to actions of cyclic 3',5'-AMP and carbamycholine. J. Membr. Biol. 35:159-173.

31. Zimmerman, T. W., J. W. Dobbins, and H. J. Binder. 1983. Role of calcium in the regulation of colonic secretion in the rat. $\mathrm{Am}$. J. Physiol. 244:G552-G560.

32. Binder, H. J. 1974. Intestinal oxalate absorption. Gastroenterology. 67:441-446.

33. Schwartz, S. E., J. Q. Stauffer, L. W. Burgess, and M. Charney. 1980. Oxalate uptake by everted sacs of rat colon: regional differences and the effects of $\mathrm{pH}$ and ricinoleic acid. Biochim. Biophys. Acta. 596:404-413.

34. Freel, R. W., M. Hatch, D. L. Earnest, and A. M. Goldner. 1980. Oxalate transport across the isolated rat colon: a re-examination. Biochem. Biophys. Acta. 600:838-843.

35. Hatch, M., R. W. Freel, A. M. Goldner, and D. L. Earnest. 1982. Active colonic oxalate absorption is mediated by chloridebicarbonate exchange system. Clin. Res. 30:283A. (Abstr.) 